\title{
Nature of the Interstitials in Titanium Dioxide and Their Impact on Transmission Coefficient: $A \boldsymbol{b}$ Initio Calculations
}

\author{
Lei Li, ${ }^{1}$ Changfu Xia, ${ }^{2}$ Wenshi Li, ${ }^{1}$ Aimin Ji, ${ }^{3}$ Canyan Zhu, ${ }^{3}$ Lijun Zhang, ${ }^{3}$ \\ Ziou Wang, ${ }^{1}$ Jianfeng Yang, ${ }^{1}$ and Ling-Feng $\mathrm{Mao}^{3}$ \\ ${ }^{1}$ Institute of Intelligent Structure and System, School of Electronics \& Information Engineering, Soochow University, \\ Suzhou 215006, China \\ ${ }^{2}$ The 26th Institute of China Electronics Technology Group Corporation, Chongqing 400060, China \\ ${ }^{3}$ Institute of Intelligent Structure and System, Soochow University, Suzhou 215006, China \\ Correspondence should be addressed to Ling-Feng Mao; lingfengmao@suda.edu.cn
}

Received 27 March 2015; Revised 28 April 2015; Accepted 29 April 2015

Academic Editor: Stefano Bellucci

Copyright (C) 2015 Lei Li et al. This is an open access article distributed under the Creative Commons Attribution License, which permits unrestricted use, distribution, and reproduction in any medium, provided the original work is properly cited.

\begin{abstract}
The $a b$ initio calculations about the properties of the interstitials doping in the rutile $\mathrm{TiO}_{2}$ and their impact on the transport coefficients are reported. As the doping of the $\mathrm{Zr}$ or Ti interstitials in the $\mathrm{TiO}_{2}$, the lattice $\mathrm{Ti}^{4+}$ ions acquire the excess electrons so reduced to the $\mathrm{Ti}^{3+}$ or $\mathrm{Ti}^{2+}$ ions. However, the $\mathrm{Cu}$ interstitials could not lose enough electrons to reduce the lattice $\mathrm{Ti}^{4+}$ ions. Furthermore, the Ti or $\mathrm{Cu}$ interstitials in the $\mathrm{ZrO}_{2}$ also are unable to promote the lattice $\mathrm{Zr}^{4+}$ ions to form the lattice $\mathrm{Zr}^{3+}$ or $\mathrm{Zr}^{2+}$ ions. The high transport coefficients are observed in the defected $\mathrm{TiO}_{2}$ with the $\mathrm{Ti}$ or $\mathrm{Zr}$ interstitials as the high concentration of the $\mathrm{Ti}^{3+}$ or $\mathrm{Ti}^{2+}$ ions. So, the $\mathrm{Zr}$ interstitials are the favorable choice for the extra-doping to improve the transport properties in the $\mathrm{TiO}_{2}$-based resistive random access memory.
\end{abstract}

\section{Introduction}

In the recent years, the resistive random access memory (ReRAM) has been extensively studied due to its high operation speed, the long retention time, and the low power consumption. It always uses the metal-insulator-metal as the basic structure. Various transition metal oxides, such as $\mathrm{TiO}_{2}$, $\mathrm{CuO}, \mathrm{HfO}_{2}$, and $\mathrm{ZrO}_{2}$, are applied as the insulator of the ReRAM cells $[1,2]$. For the preeminent resistive switching characteristic, $\mathrm{TiO}_{2}$ is one of the most promising materials for the insulator in ReRAM. Up to now, one of the major challenges is the large variation of the switching parameters induced by the random formation of the conduction path under the external electrical fields. It needs to clarify the resistive switching mechanisms to solve this problem and finally improve the reliability of these devices. For the insulator of the rutile $\mathrm{TiO}_{2}$, the leakage currents are often explained with the gap states originating from the point defects, such as the oxygen vacancies and $\mathrm{Ti}$ interstitials [3-8]. In contrast, these defects could improve the resistive switching characteristics. When doping in the rutile $\mathrm{TiO}_{2}$, it is necessary to investigate the role of the interstitials in the conduction path for the resistive switching, such as $\mathrm{Cu}$ interstitials and $\mathrm{Zr}$ interstitials. Many novel systems, such as $\mathrm{Pt} / \mathrm{ZrO}_{2} / \mathrm{TiO}_{2} / \mathrm{Pt}, \mathrm{Pt} / \mathrm{Ti} / \mathrm{TiO}_{2} / \mathrm{Pt}, \mathrm{Cu} / \mathrm{ZrO}_{2}: \mathrm{Cu} / \mathrm{Pt}$, and $\mathrm{Cu} / \mathrm{ZrO}_{2}: \mathrm{Ti} / \mathrm{Pt}$, have been proposed to explain the resistive switching mechanism [9-11]. In this work, we would address the impact of the $\mathrm{Cu} / \mathrm{Ti} / \mathrm{Zr}$ interstitials on the fine structure of the defected $\mathrm{TiO}_{2}$.

\section{Method}

The structural model of the perfect rutile $\mathrm{TiO}_{2}$ is presented with a primitive cell (lattice parameters $a=b=4.594 \AA$, $c=2.959 \AA)$. We construct $1 \times 1 \times 6$ supercells $(a=b=$ $4.594 \AA, c=17.754 \AA$ ) as the initial structural model. The Ti interstitials are doped in the $1 \times 1 \times 6$ supercells at $(2.297,2.297$, $2.959),(2.297,2.297,8.877)$, and $(2.297,2.297,14.795)$. The $\mathrm{Cu}$ interstitials or the $\mathrm{Zr}$ interstitials are doped in the defected $\mathrm{TiO}_{2}$ at the same coordinates as Ti interstitials as shown in Figure $1(\mathrm{a})$. We build the $1 \times 1 \times 3$ supercells of the defected $\mathrm{ZrO}_{2}(a=b=5.070 \AA, c=15.210 \AA)$ with the Ti interstitials 


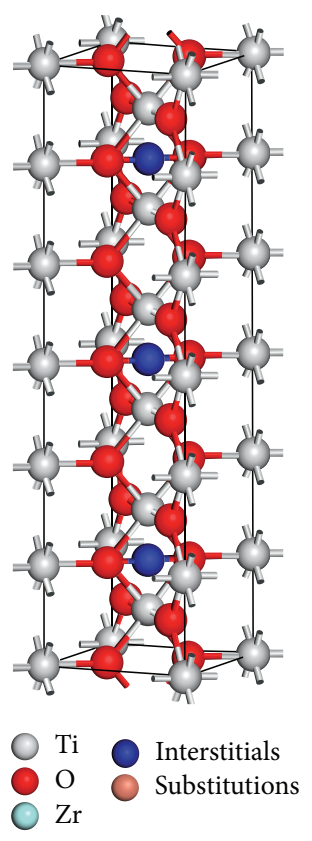

(a)

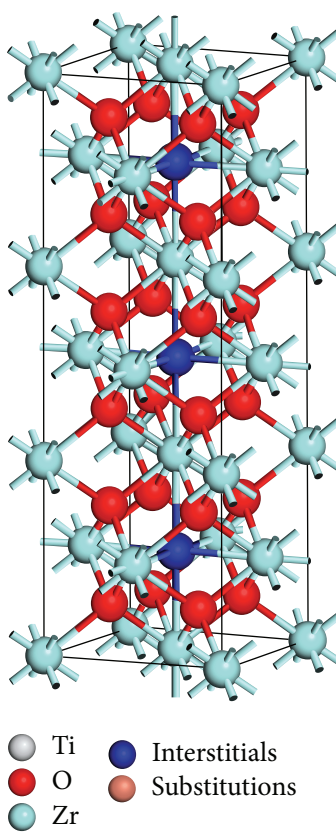

(b)

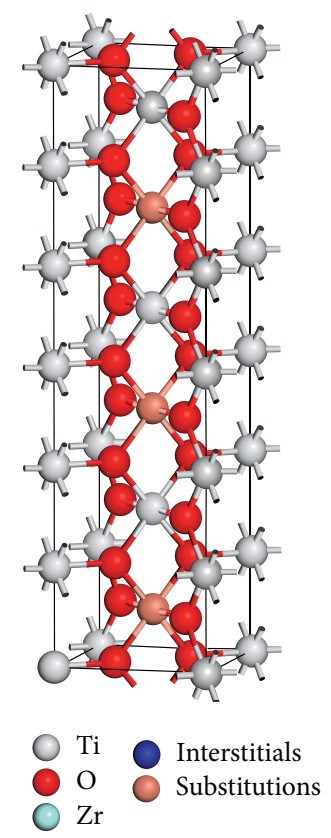

(c)

Figure 1: Configuration of the defected $\mathrm{TiO}_{2}$ with the interstitials (a), the defected $\mathrm{ZrO}_{2}$ with the interstitials (b), and the defected TiO $\mathrm{O}_{2}$ with the substitutions (c).

or the $\mathrm{Cu}$ interstitials at $(2.535,2.535,2.630),(2.535,2.535$, $7.690)$, and $(2.535,2.535,12.716)$ as shown in Figure $1(\mathrm{~b})$. For the comparison, we use the $1 \times 1 \times 6$ supercells of the defected $\mathrm{TiO}_{2}$ with the $\mathrm{Cu}$ substitutions or the $\mathrm{Zr}$ substitutions for the Ti atoms at $(2.535,2.535,1.480),(2.535,2.535,7.398)$, and $(2.535,2.535,13.316)$ as shown in Figure $1(\mathrm{c})$. All the structures are relaxed under the electric field of $10.4 \mathrm{MV} / \mathrm{cm}$.

We explore the $\mathrm{DMol}^{3}$ program to carry out the spin polarized density functional calculations. These geometries are optimized using the double-numeric quality basis set (DNP) equal to 3.5, together with the PBE (Perdew, Burke, and Ernzerhof) gradient-corrected functional to describe the exchange and correlation effects [12]. Special sampling points in the Brillouin zone are used with the MonkhorstPack schemes of $3 \times 3 \times 1 \mathrm{k}$-point meshes [13]. A thermal smearing of $0.01 \mathrm{Ha}(1 \mathrm{Ha}=27.2114 \mathrm{eV})$ and a global orbital cutoff of $5.2 \AA$ are employed to improve computational performance. The wave basis set with a cutoff energy of $400.0 \mathrm{eV}$ is adopted. The tolerances of energy, gradient, and displacement convergence for the geometric optimization and energy calculation are set to $1 \times 10^{-5} \mathrm{Ha}, 2 \times 10^{-3} \mathrm{Ha} / \AA$, and $5 \times 10^{-3} \AA$, respectively. We further use Virtual NanoLab program to calculate the transmission coefficient with the DFT-PBE function at $300 \mathrm{~K}$. The cutoff of the grid mesh is set to 40 hartree. The basis sets of double zetas and polarization orbitals (DZP) are performed in the transport simulations.

\section{Results and Discussions}

Figure 2 depicts the slices of the deformation electron density in [110] for the defected $\mathrm{TiO}_{2}$ with the $\mathrm{Cu}$ interstitials (a), Ti interstitials (b), Zr interstitials (c), and the corresponding white-black views $(\mathrm{d}-\mathrm{f})$. The gray balls and the red balls indicate $\mathrm{Ti}$-atoms and $\mathrm{O}$-atoms, respectively. The brown balls, the blue balls, and the green balls separately stand for the $\mathrm{Cu}$ interstitials, Ti interstitials, and $\mathrm{Zr}$ interstitials. We set the spectrum of the deformation electron density to the blue-green-red from -0.1 to 0.1 electrons $/ \AA^{3}$. The deficiencies for the electrons are indicated in blue color, while the enrichment is in red color. In Figure 2(a), it would be seen that some regions with blue color lie around the $\mathrm{Cu}$ interstitials. They are also correspondingly found in the dark round in Figure 2(d). It means that the $\mathrm{Cu}$ interstitials lose the electrons to form the ionic bonds with the nearby Oions. The weak electron-clouds with light red locate among the $\operatorname{Ti}(2)$ atom and the $\operatorname{Ti}(3)$ atom, the $\operatorname{Ti}(4)$ atom and the $\operatorname{Ti}(5)$ atom. The light gray in the corresponding regions is found in Figure 2(d). It means the formation of the weak Ti-Ti bonds as the doping of the $\mathrm{Cu}$ interstitials. In Figure 2(b), the aggregated electron-clouds with the dark red color would be seen among the lattice Ti-ions and the Ti interstitials. These red electron-clouds seat at the bonds of the Ti-Ti bonds. They are corresponding to the belt-like dark regions in Figure 2(e). In Figure 2(c), the aggregated electron-clouds between the Ti-ions and the $\mathrm{Zr}$ interstitials show the weaker than those in Figure 2(b). The more irregular belt-like dark regions are shown in Figure 2(f). The introduction of the Ti interstitials and the $\mathrm{Zr}$ interstitials could not induce the formation of the ionic bonds with the lattice $\mathrm{O}$-ions. We would employ the Mulliken charges to explain the difference of the deformation electron density [14].

Figure 3 shows the Mulliken charge of the three types of the defected $\mathrm{TiO}_{2}$ with the interstitials. Ti(1)-Ti(6) indicate the lattice Ti-ions, and $i(7)-i(9)$ mean the interstitials 


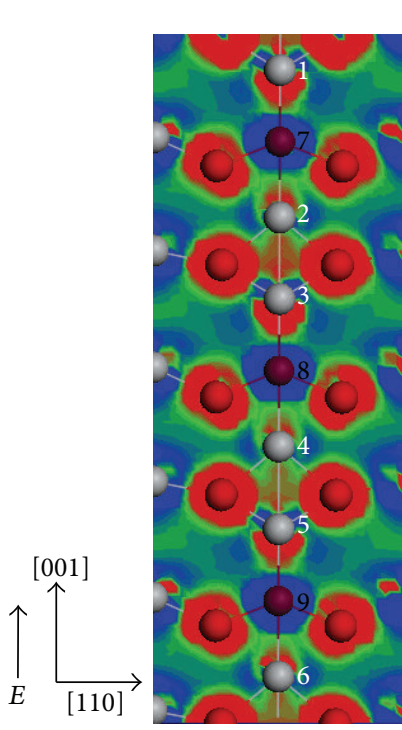

(a)
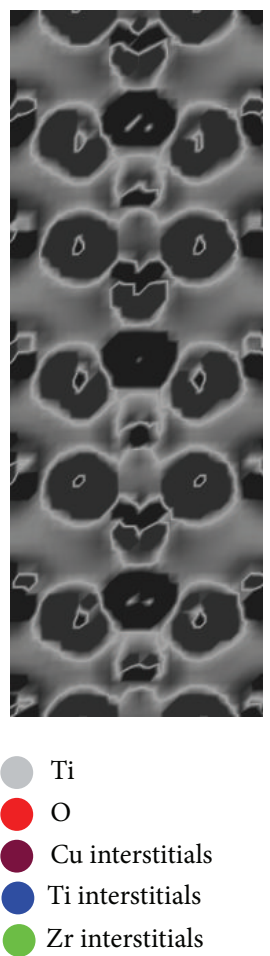

(d)

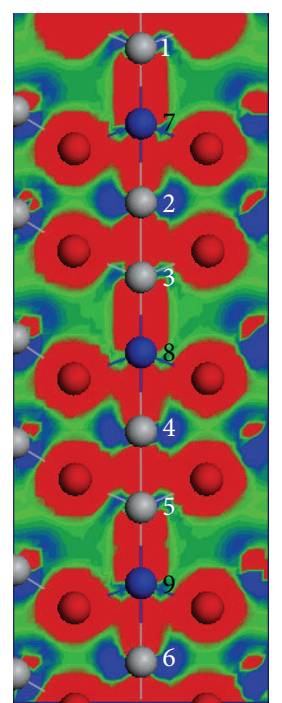

(b)
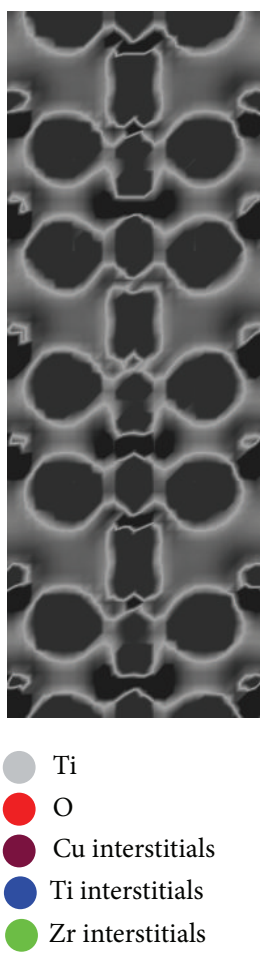

(e)

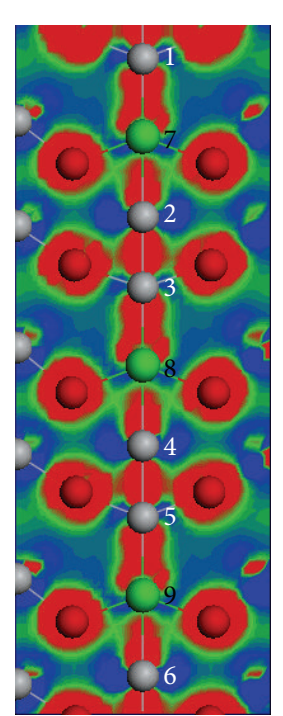

(c)

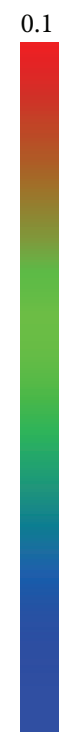

0.1
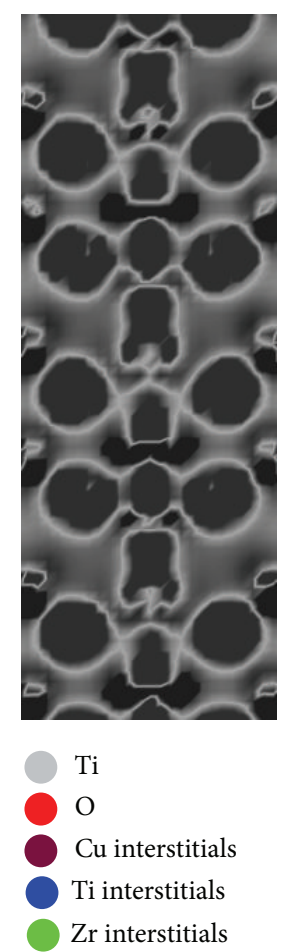

(f)

FIgURE 2: Deformation electron density in [110] for the defected $\mathrm{TiO}_{2}$ with the $\mathrm{Cu}$ interstitials (a), Ti interstitials (b), $\mathrm{Zr}$ interstitials (c), and the corresponding white-black views $(\mathrm{d}-\mathrm{f})$.

with Number 7-Number 9 as shown in Figure 2. We use the $\mathrm{Ti}_{12} \mathrm{Cu}_{3} \mathrm{O}_{24}, \mathrm{Ti}_{15} \mathrm{O}_{24}$, and $\mathrm{Ti}_{12} \mathrm{Zr}_{3} \mathrm{O}_{24}$ to stand for the structures in Figure 2. The Mulliken charges of the Ti-ions in perfect $\mathrm{TiO}_{2}$ are $1.721 \mathrm{eV}$. The Mulliken charges of the lattice Ti-ions in $\mathrm{Ti}_{12} \mathrm{Zr}_{3} \mathrm{O}_{24}$ (49.9\% of $1.721 \mathrm{eV}$ ) are smaller than those in $\mathrm{Ti}_{15} \mathrm{O}_{24}(66.8 \%)$ and $\mathrm{Ti}_{12} \mathrm{Cu}_{3} \mathrm{O}_{24}(80.4 \%)$. The Mulliken charges for the $\mathrm{Zr}$ interstitials in $\mathrm{Ti}_{12} \mathrm{Zr}_{3} \mathrm{O}_{24}$ are larger than those for the $\mathrm{Ti}$ interstitials in $\mathrm{Ti}_{15} \mathrm{O}_{24}$ and $\mathrm{Cu}$ interstitials in $\mathrm{Ti}_{12} \mathrm{Cu}_{3} \mathrm{O}_{24}$. The Mulliken charges for the lattice $\mathrm{Zr}$ ions in the perfect $\mathrm{ZrO}_{2}$ are $2.292 \mathrm{eV}$. So the $\mathrm{Zr}$ interstitials in $\mathrm{Ti}_{12} \mathrm{Zr}_{3} \mathrm{O}_{24}$ lose more electrons and the corresponding $\mathrm{Ti}$ atoms are reduced to the $\mathrm{Ti}^{3+}$ or $\mathrm{Ti}^{2+}$ ions with the smallest Mulliken charges. The electric field of $10.4 \mathrm{MV} / \mathrm{cm}$ redisperses the electrons which transfer between the lattice Ti atoms and the interstitials. It would explain the difference of Mulliken charges among the $\operatorname{Ti}(1)-\operatorname{Ti}(6)$ atoms. 


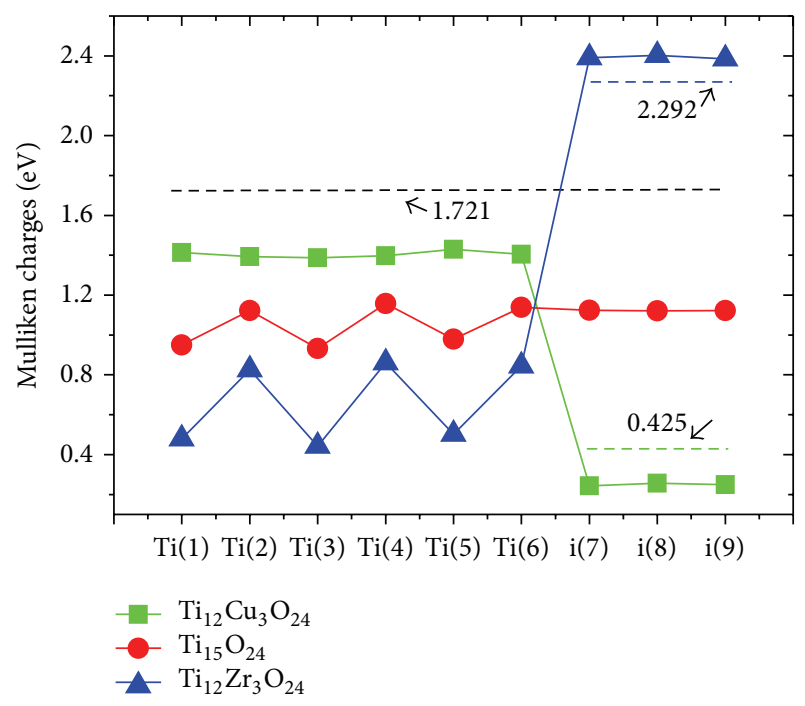

FIgURE 3: Mulliken charges in the defected $\mathrm{TiO}_{2}$ with the interstitials.

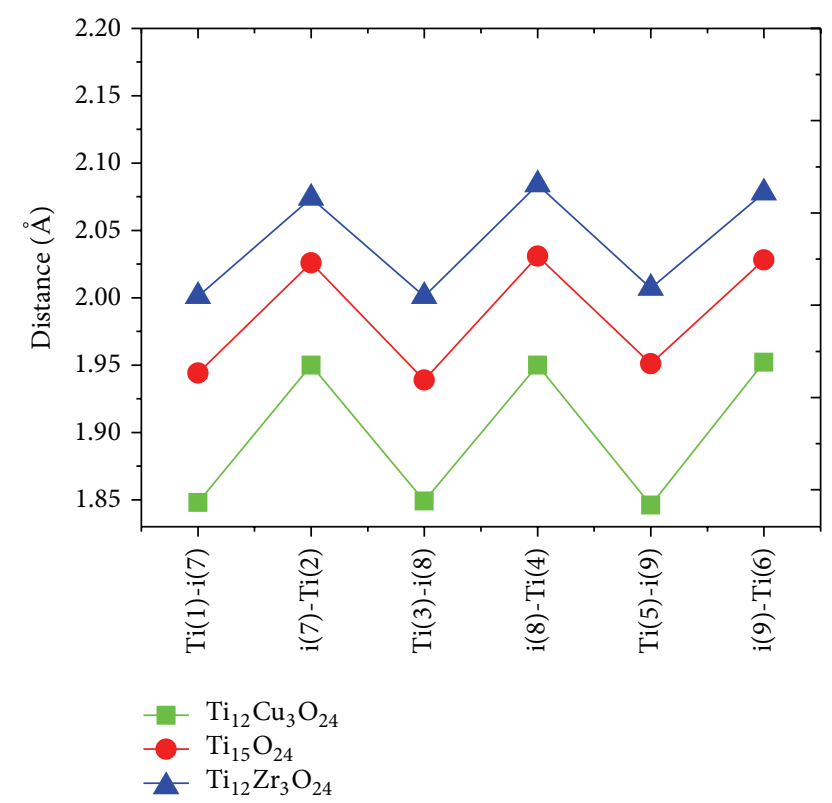

Figure 4: Distances among the lattice Ti-ions and the interstitials in the defected $\mathrm{TiO}_{2}$ with the interstitials.

Figure 4 shows the distances among the lattice Tiions and the interstitials. The $\operatorname{Ti}(1)-i(7)$ means the distance between the lattice $\mathrm{Ti}(1)$ atom and the interstitial of Number 7. The distances between the interstitials and the lattice Tiions in the $\mathrm{Ti}_{12} \mathrm{Cu}_{3} \mathrm{O}_{24}$ are shorter than those in $\mathrm{Ti}_{15} \mathrm{O}_{24}$ and $\mathrm{Ti}_{12} \mathrm{Zr}_{3} \mathrm{O}_{24}$.

Figure 5 shows the partial density of states for the defected $\mathrm{TiO}_{2}$ with the $\mathrm{Cu}$ interstitials (a), Ti interstitials (b), and $\mathrm{Zr}$ interstitials (c). The curves with the light green color, the red color, the blue color, the dark green color, and the pink color separately indicate the $\mathrm{p}$ states, the $\mathrm{d}$ states, the sum states, the DOS induced by the Ti-ions $(\operatorname{Ti}(1)-\operatorname{Ti}(6))$, and the DOS induced by the interstitials. In Figure 5, all the conduction bands are split into two parts, $t_{2 g}$ and $e_{g}$ orbitals of the Tiions. The $t_{2 g}$ states have a lower energy than the $e_{g}$ states. They originate from the antibonding interactions of the Ti- $3 \mathrm{~d}$ states and the O-2p states due to the doping of the interstitials. The Fermi energy level lies in the defect energy level near the valence band maximum in Figure 5(a) and in the valence bands in Figures 5(b) and 5(c). It is corresponding to the two types of the conduction mechanisms, the hole-dominated and the electron-dominated, respectively. The defect energy levels lie on the top of the valence band maximum (VBM) in Figure 5(b), much deeper states than the others in Figures 5(a) and 5(c). They are largely composed of the lattice Ti-3d states rather than the $\mathrm{Cu}-3 \mathrm{~d}$ states or the $\mathrm{Zr}-3 \mathrm{~d}$ states. It also shows the strong hybridization between the O-2p and the $\mathrm{Ti}$ $3 \mathrm{~d}$ orbitals. So it induces the electrons strongly localized at the $\mathrm{Ti}^{3+}$ or $\mathrm{Ti}^{2+}$ trap centers.

In Figures 2-5, it could be clearly seen that the interstitials in the defected $\mathrm{TiO}_{2}$ can induce the lattice $\mathrm{Ti}$ atoms to Tiions with the lower valence. Next, we continue to consider the defected $\mathrm{ZrO}_{2}$ with the Ti interstitials and the $\mathrm{Cu}$ interstitials.

Figure 6 depicts the deformation electron densities in [110] and the partial density of states for the defected $\mathrm{ZrO}_{2}$ with the $\mathrm{Ti}$ interstitials $(\mathrm{a}, \mathrm{c})$ or $\mathrm{Cu}$ interstitials $(\mathrm{b}, \mathrm{d})$. Figure 6(e) shows the partial density of states for the perfect $\mathrm{ZrO}_{2}$. In Figure 6(a), less electron-cloud with red color locates around the lattice $\mathrm{Zr}$-ions and the Ti interstitials. The Mulliken charges of the Ti interstitials are equal to $0.061 \mathrm{eV}$, $0.058 \mathrm{eV}$, and $0.063 \mathrm{eV}$. It means that these Ti interstitials lose little electrons and keep the metallic characteristics. The Mulliken charges of the lattice $\mathrm{Zr}$-ions are about $2.076 \mathrm{eV}$ ( $90.5 \%$ of $2.292 \mathrm{eV}$ ), which show the less reduction by $\mathrm{Ti}$ interstitials. In Figure 6(b), some regions with weak blue color lie around the $\mathrm{Cu}$ interstitials. The Mulliken charges of the $\mathrm{Cu}$ interstitials are equal to about $-0.058 \mathrm{eV},-0.145 \mathrm{eV}$, and $-0.031 \mathrm{eV}$. It means that these $\mathrm{Cu}$ interstitials even gain little electrons. The Mulliken charges of the lattice $\mathrm{Zr}$ interstitials are about $2.105 \mathrm{eV}$ ( $91.8 \%$ of $2.292 \mathrm{eV})$, which also show the less reduction by $\mathrm{Cu}$ interstitials.

In Figure 6(c), the Fermi energy level locates in the defect energy levels on the bottom of the conduction band minimum, which means the $n$-type semiconductor characteristics. The defect energy levels mainly originate from the contribution of Ti-3d atom orbital of the Ti interstitials. The band gap is $0 \mathrm{eV}$. In Figure 6(d), the defect energy levels on the top of the valence band maximum mainly originate from the cocontribution of the $\mathrm{Cu}-3 \mathrm{~d}$ atom orbital of the $\mathrm{Cu}$ interstitials and the O-2p atom orbital of the lattice Oions. They shift the valence bands edge to the higher energy to narrow the band gap to $2.176 \mathrm{eV}$, which appears to be smaller than the band gap of $2.573 \mathrm{eV}$ in the perfect $\mathrm{ZrO}_{2}$ in Figure 6(e). The Fermi energy level locates on the bottom of the conduction band minimum, which also means the $n$-type semiconductor characteristics.

We have addressed the defected $\mathrm{TiO}_{2}$ and the defected $\mathrm{ZrO}_{2}$ with the interstitials. The $\mathrm{Zr}$ interstitials in the defected $\mathrm{TiO}_{2}$ reduce the lattice $\mathrm{Ti}$-ions to the $\mathrm{Ti}^{3+}$ or $\mathrm{Ti}^{2+}$ ions. However, the $\mathrm{Ti}$ interstitials in the defected $\mathrm{ZrO}_{2}$ do not 


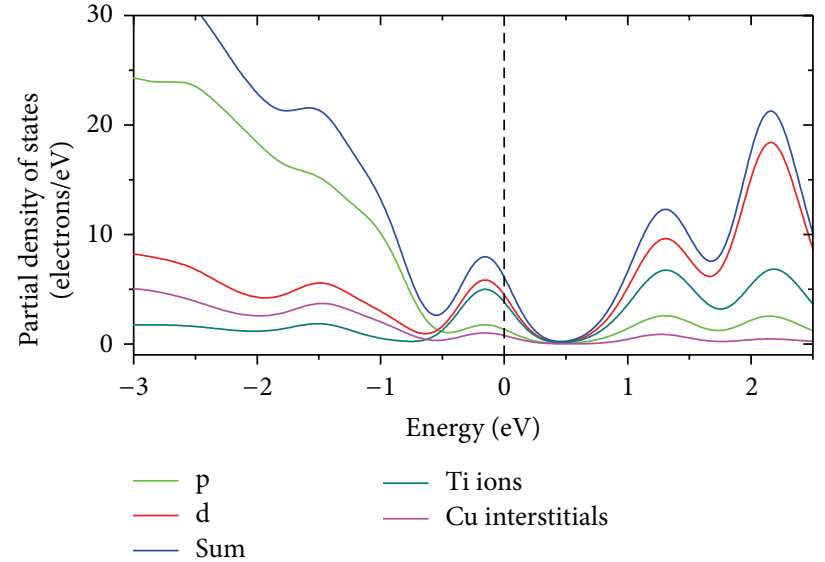

(a)

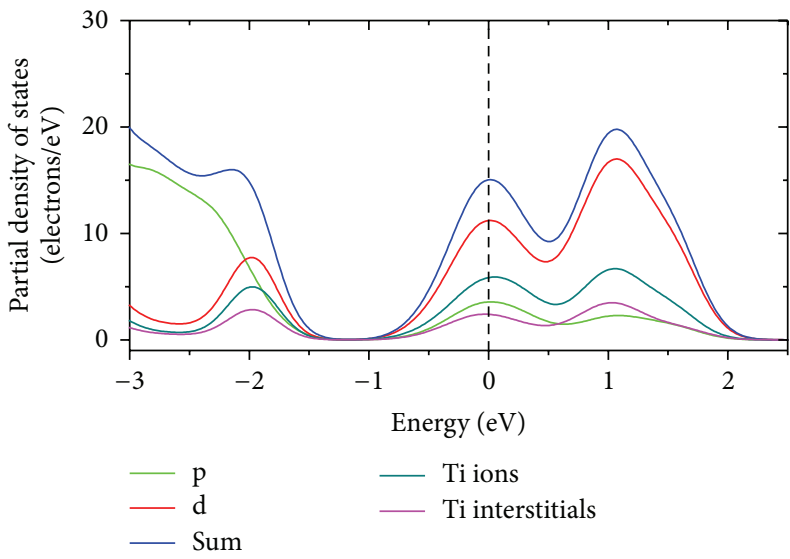

(b)

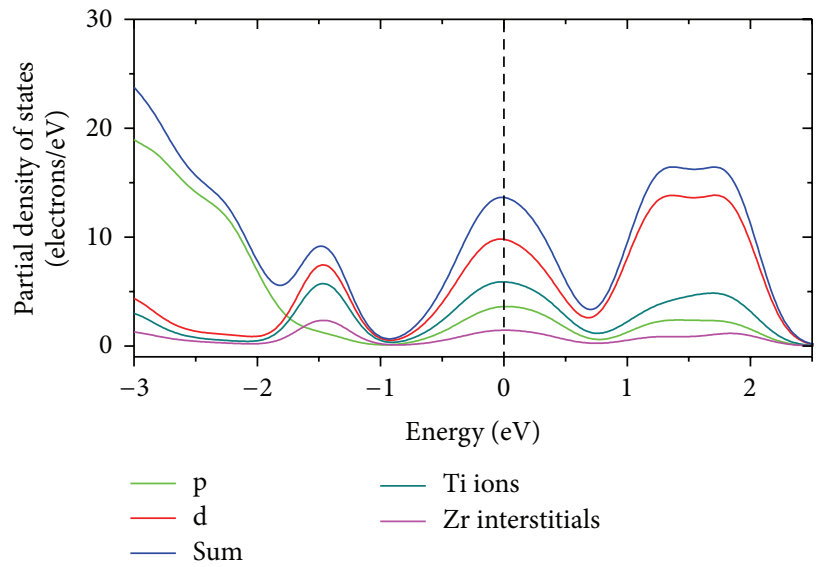

(c)

Figure 5: Partial density of states for the defected $\mathrm{TiO}_{2}$ with the $\mathrm{Cu}$ interstitials (a), Ti interstitials (b), and $\mathrm{Zr}$ interstitials (c).

reduce the lattice $\mathrm{Zr}$-ions. Next, the $\mathrm{Cu}$ substitutions or the $\mathrm{Zr}$ substitutions for the lattice $\mathrm{Ti}$ atoms in the defected $\mathrm{TiO}_{2}$ would be considered.

Figure 7 shows the partial sectional view of the structures in [110] for the defected $\mathrm{TiO}_{2}$ with $\mathrm{Cu}$ substitutions (a) and Zr substitutions (b). The gray balls, the red ball, the pink balls, and the green ball indicate the $\mathrm{Ti}$ atoms, the $\mathrm{O}$ atoms, the $\mathrm{Cu}$ substitutions, and the $\mathrm{Zr}$ substitutions, respectively. The data with green color means the Mulliken charges. The Mulliken charges of the $\mathrm{Cu}$ substitutions and $\mathrm{Zr}$ substitutions in the defected $\mathrm{TiO}_{2}$ are larger than those in the perfect $\mathrm{CuO}$ $(0.735 \mathrm{eV})$ and in the perfect $\mathrm{ZrO}_{2}(2.292 \mathrm{eV})$. The Mulliken charges of the Ti-ions are larger than $1.59 \mathrm{eV}$, which appear to be distinct to those in Figure 3. So the $\mathrm{Cu}$ substitutions or $\mathrm{Zr}$ substitutions in the defected $\mathrm{TiO}_{2}$ always induce the formation of the $\mathrm{Ti}^{4+}$ ions.

Figure 8 shows the partial density of states for the defected $\mathrm{TiO}_{2}$ with $\mathrm{Cu}$ substitutions (a) and $\mathrm{Zr}$ substitutions (b). The curves with the light green color, the red color, the blue color, and the dark green color separately indicate the $\mathrm{p}$ states, the $d$ states, the sum states, and the DOS induced by the substitutions. The Fermi energy levels locate on the top of the valence band maximum but with the lower energy in
Figure 8(a) than that in Figure 8(b). The defect energy levels in Figure 8(a) lie on the top of the valence bands maximum. So they shift the valence bands edge to the higher energy to narrow the band gap to $1.360 \mathrm{eV}$. The band gap in Figure 8(b) is $1.632 \mathrm{eV}$, larger than that in Figure 8(a). These band gaps are still larger than those in Figure 5 in the defected $\mathrm{TiO}_{2}$ with the interstitials.

Figure 9 shows the transmission coefficients for the defected $\mathrm{ZrO}_{2}$ with the $\mathrm{Cu}$ interstitials (a), the Ti interstitials (b), the defected $\mathrm{TiO}_{2}$ with the $\mathrm{Zr}$ interstitials (c), the $\mathrm{Ti}$ interstitials (d), and the Cu interstitials (e). In Figures 9(c) and 9(d), no transmission gap would be found for the defected $\mathrm{TiO}_{2}$ with the interstitials, while a transmission gap of $0.8 \mathrm{eV}$ in Figure 9(b) in the defected $\mathrm{ZrO}_{2}$ with the Ti interstitials was found. In Figure 9(a), the transmission coefficient is equal to zero at $-2.1 \mathrm{eV} \sim-0.6 \mathrm{eV}$ which is consistent with the density of states as shown in Figure 6(d). In Figures 9(a)$9(\mathrm{~d})$, the transport coefficients appear oscillated above $0 \mathrm{eV}$. In comparison to Figure 2 and Figure 6, we find that the oscillations originate from the coupling of the electrons and the holes. In Figure 2(b), the large blocks of the electrons enrichment with red color are observed between the $\mathrm{O}$ ions and the Ti-ions, while the relatively small blocks of the 


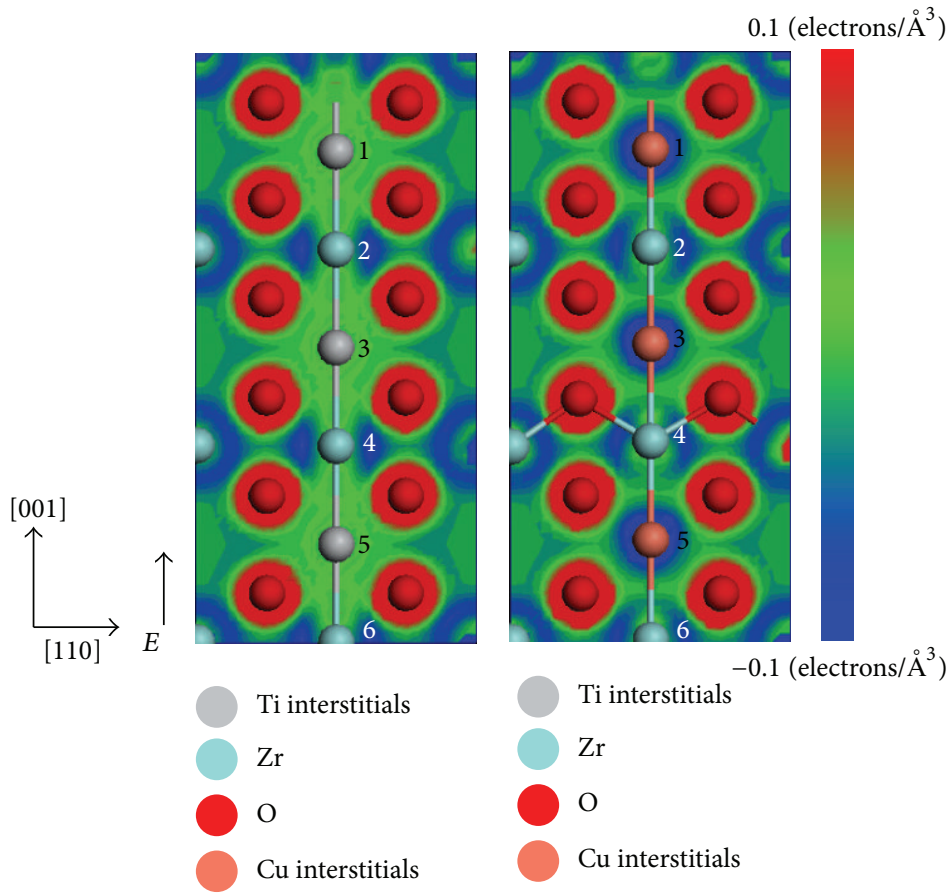

(a)

(b)

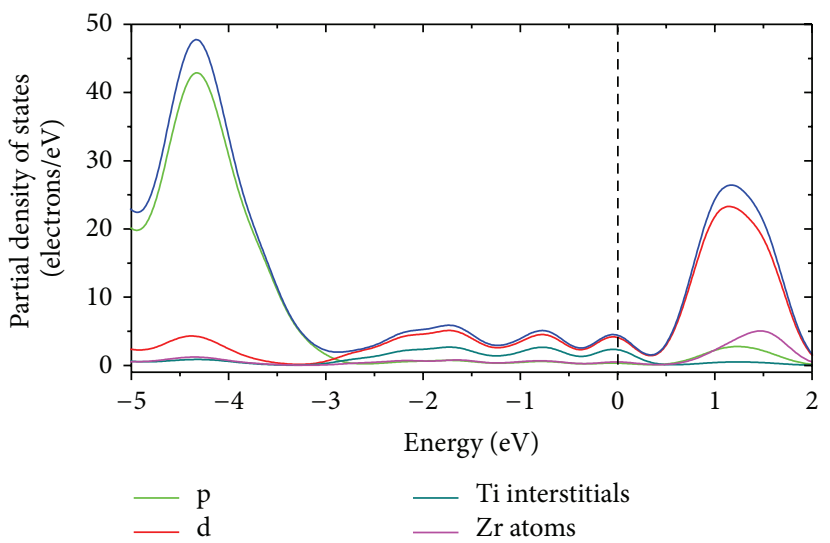

(c)

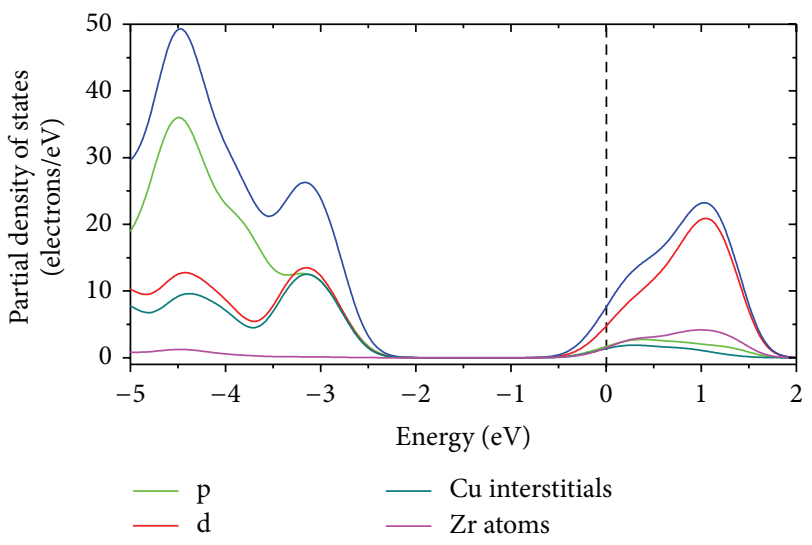

(d)

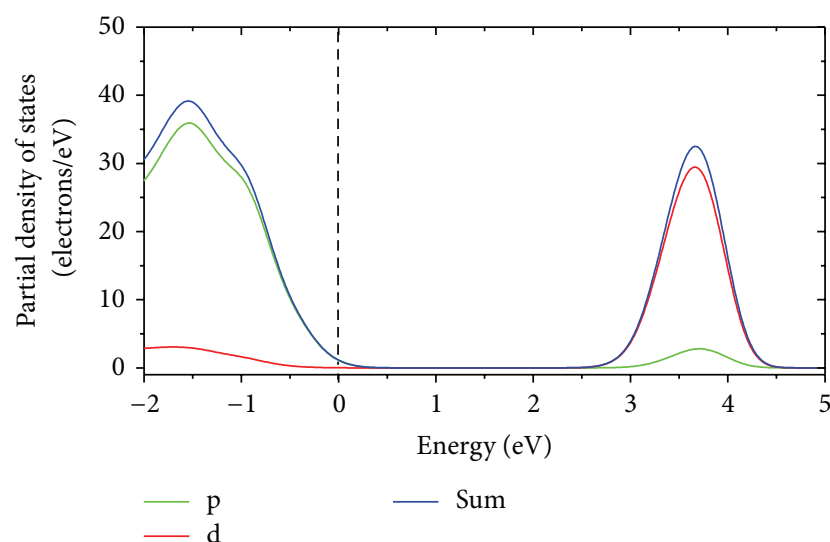

(e)

Figure 6: Deformation electron density in [110] for the defected $\mathrm{ZrO}_{2}$ with the Ti interstitials (a) and Cu interstitials (b); partial density of states for the defected $\mathrm{ZrO}_{2}$ with the Ti interstitials (c) and $\mathrm{Cu}$ interstitials (d); (e) density of states for the perfect $\mathrm{ZrO}_{2}$. 


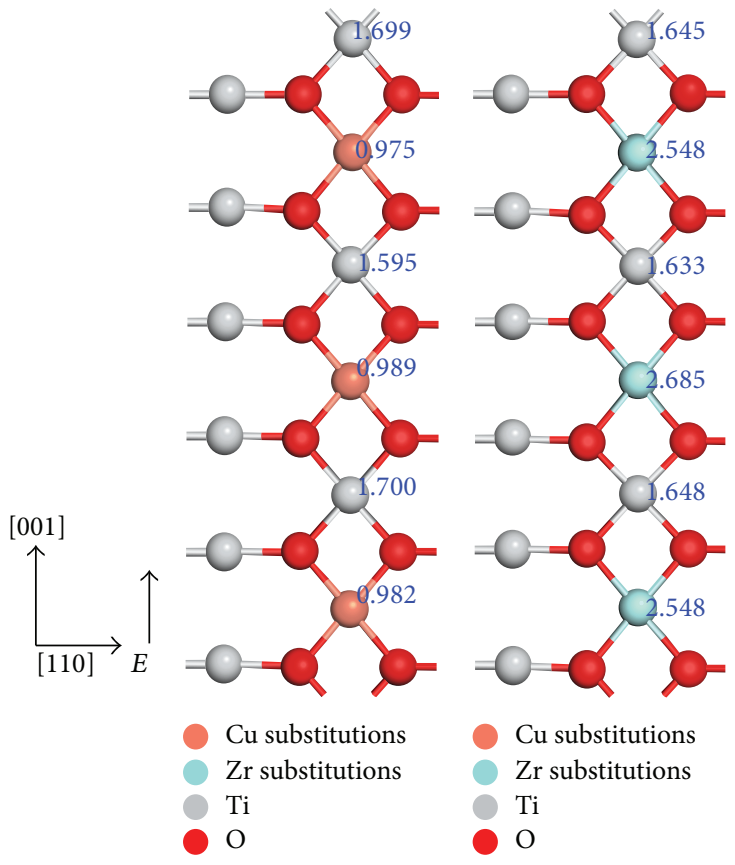

(a)

(b)

Figure 7: Partial sectional view in [110] for the defected $\mathrm{TiO}_{2}$ with the $\mathrm{Cu}$ substitutions (a) and $\mathrm{Zr}$ substitutions (b).

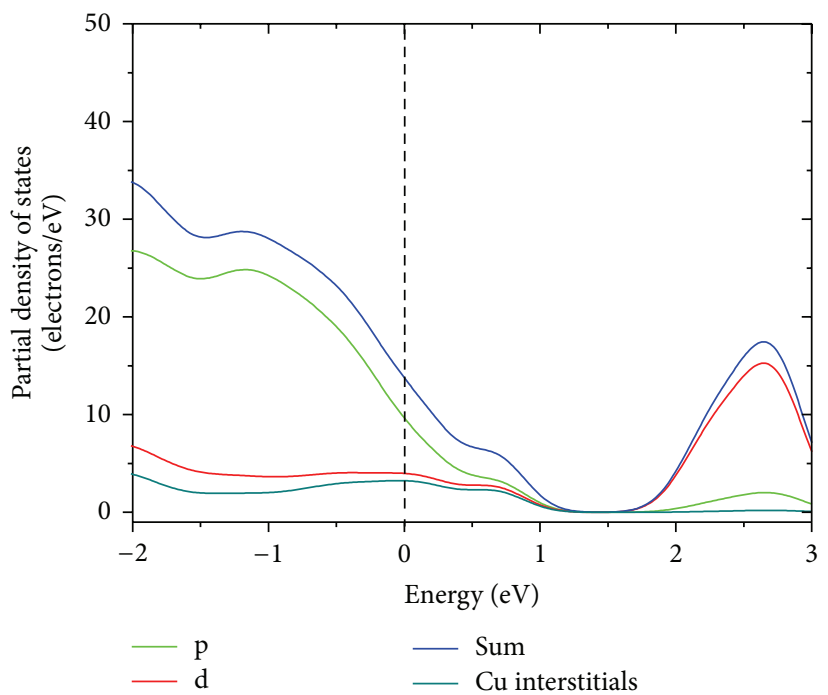

(a)

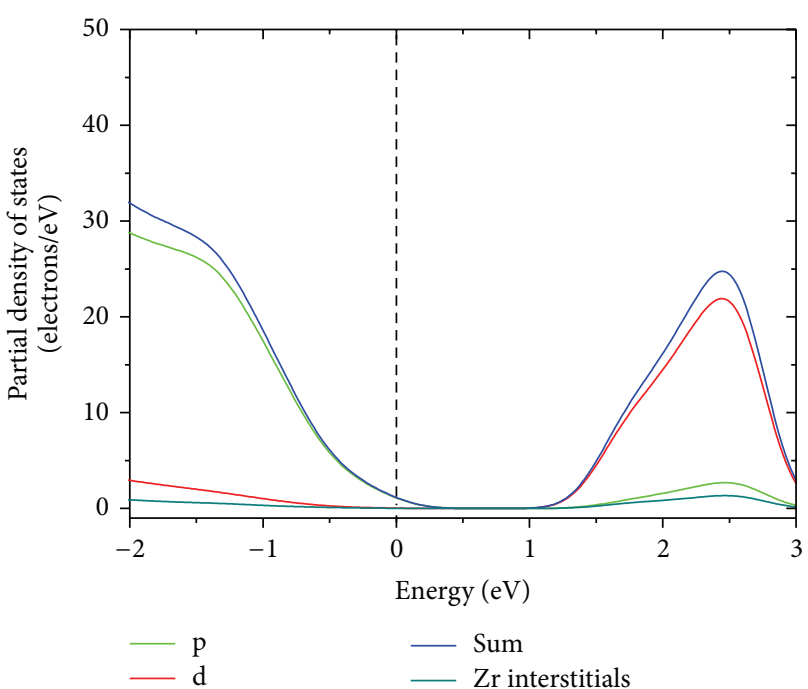

(b)

FIgURE 8: Partial density of states for the defected $\mathrm{TiO}_{2}$ with the $\mathrm{Cu}$ substitutions (a) and $\mathrm{Zr}$ substitutions (b).

electrons deficiency with blue color or light green color are also found between them. It induces the weak coupling of the electrons and the holes. So the weaker oscillations are found in Figure 9(d) in the defected $\mathrm{TiO}_{2}$ with the Ti interstitials. In contrast, the large blocks of the electrons deficiency in Figure 6(a) locate around the Ti-ions and the Zr-ions. It shows the severe oscillations in Figure $9(\mathrm{~b})$ as the strong coupling of the electrons and holes in the defected $\mathrm{ZrO}_{2}$ with the Ti interstitials. The relative Fermi energy levels also could explain these phenomena. The strong hybridization between
$\mathrm{O}-2 \mathrm{p}$ and Ti-3d orbitals decreases the transport coefficients from $-1.5 \mathrm{eV}$ to $-0.5 \mathrm{eV}$ in Figure $9(\mathrm{c})$ and from $-1.3 \mathrm{eV}$ to $-0.7 \mathrm{eV}$ in Figure 9(d). The transport coefficients at $-2.0 \mathrm{eV} \sim$ $-1.5 \mathrm{eV}$ in Figure 9(c) are lower than those in Figure 9(d) as the lower DOS of the defect energy levels in Figure 5(c) in the defected $\mathrm{TiO}_{2}$ with the $\mathrm{Zr}$ interstitials. So the advanced transport coefficients are found in the defected $\mathrm{TiO}_{2}$ with the Ti interstitials and then in the defected $\mathrm{TiO}_{2}$ with the $\mathrm{Zr}$ interstitials and the worst in the defected $\mathrm{TiO}_{2}$ with the $\mathrm{Cu}$ interstitials. 


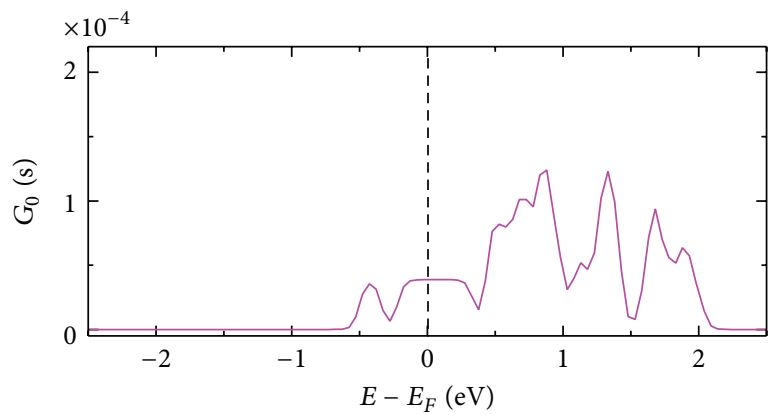

$-\mathrm{ZrO}_{2}: \mathrm{Cu}$

(a)

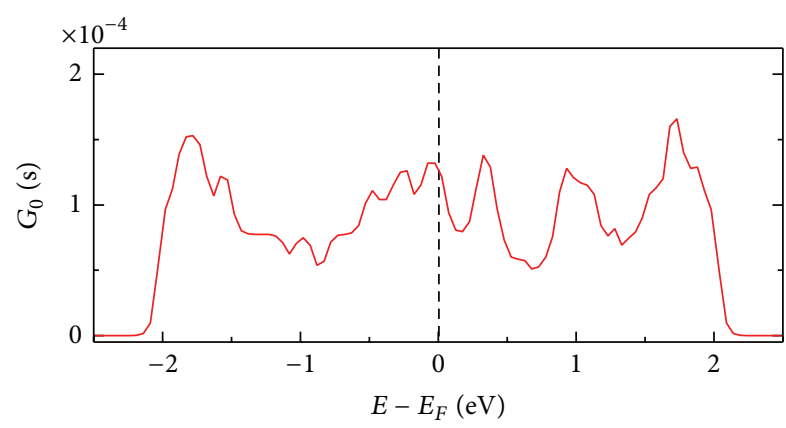

$-\mathrm{TiO}_{2}: \mathrm{Zr}$

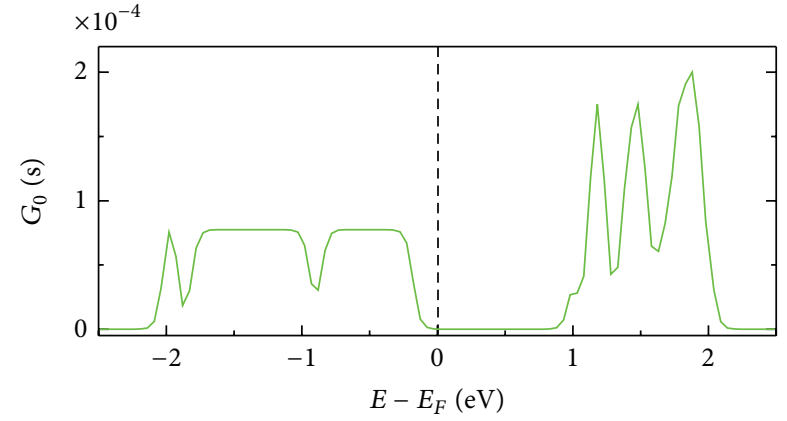

$-\mathrm{ZrO}_{2}: \mathrm{Ti}$

(b)

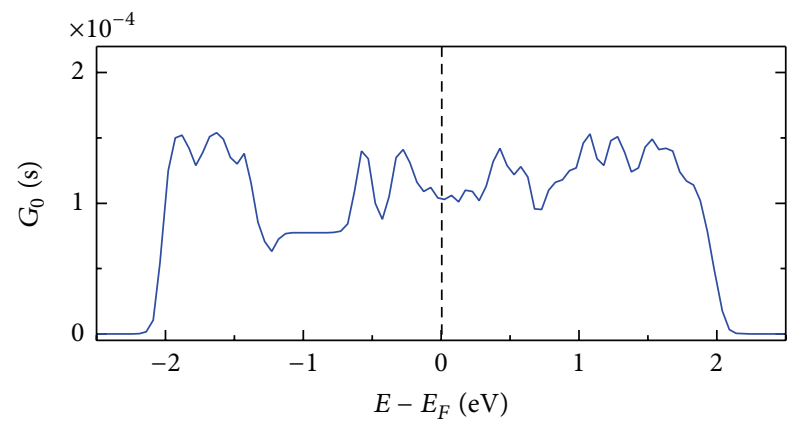

$-\mathrm{TiO}_{2}: \mathrm{Ti}$

(d)

(c)

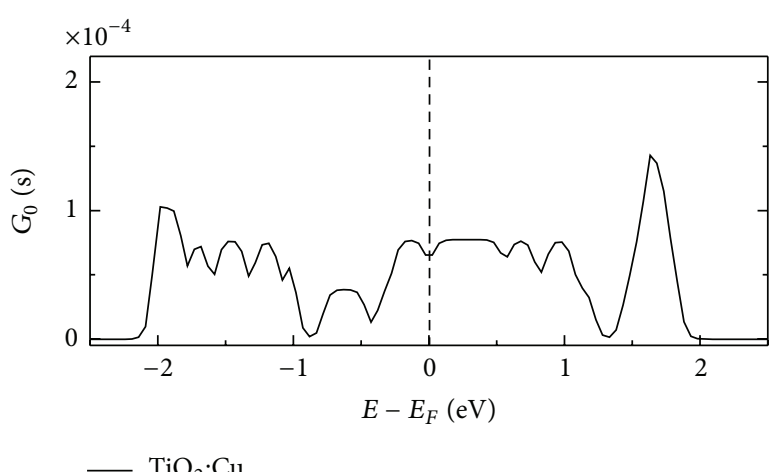

(e)

Figure 9: Transmission coefficients for the defected $\mathrm{ZrO}_{2}$ with the $\mathrm{Cu}$ interstitials (a), Ti interstitials (b), the defected $\mathrm{TiO}{ }_{2}$ with the $\mathrm{Zr}$ interstitials (c), Ti interstitials (d), and $\mathrm{Cu}$ interstitials (e).

The formation energies of the Ti interstitials, the $\mathrm{Zr}$ interstitials, and the $\mathrm{Cu}$ interstitials are $5.95 \mathrm{eV}, 8.86 \mathrm{eV}$, and $10.24 \mathrm{eV}$. The better stability of the Ti interstitials self-doping in the $\mathrm{TiO}_{2}$ improves the transport properties. For the $\mathrm{Cu}$ atoms or $\mathrm{Zr}$ atoms, their steady coordination valences with $\mathrm{O}$ atoms are +2 in $\mathrm{CuO}$ or +4 in $\mathrm{ZrO}_{2}$. In the above discussions, the doping of the $\mathrm{Zr}$ interstitials in $\mathrm{TiO}_{2}$ reduces the lattice $\mathrm{Ti}^{4+}$ ions to the $\mathrm{Ti}^{3+}$ or $\mathrm{Ti}^{2+}$ ions and leads to the higher transport coefficients than the $\mathrm{Cu}$ interstitials do. So, for the metal atoms with the valences of +4 or more in their binary oxides, their interstitials doping in $\mathrm{TiO}_{2}$ could further reduce the $\mathrm{Ti}^{4+}$ ions to the $\mathrm{Ti}^{3+}$ or $\mathrm{Ti}^{2+}$ ions rather than those with the lower valences in the binary oxides, such as +3 or +2 . We use the Fe interstitials $(+3)$ and $\mathrm{Hf}$ interstitials $(+4)$ to verify the conclusion $[15,16]$. The results of the Mulliken charges of the interstitials and the lattice $\mathrm{Ti}$ atoms would be seen in Figure 10. It is clearly seen that the Mulliken charges of the Ti-ions in $\mathrm{Ti}_{12} \mathrm{Hf}_{3} \mathrm{O}_{24}$ are much smaller than those in $\mathrm{Ti}_{12} \mathrm{Fe}_{3} \mathrm{O}_{24}$.

\section{Conclusions}

We focus on $a b$ initio calculations about the role of the interstitials doping in the rutile $\mathrm{TiO}_{2}$ and their impact on the transport coefficients. We find that the $\mathrm{Zr}$ or Ti interstitials in the $\mathrm{TiO}_{2}$ lose the electrons and induce the formation 


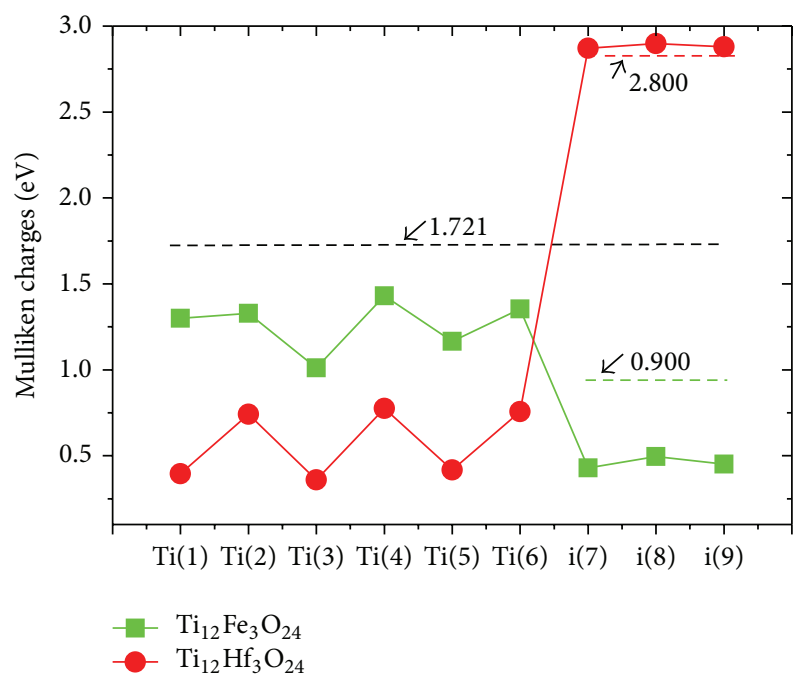

Figure 10: Mulliken charges in the defected $\mathrm{TiO}_{2}$ with the Fe or Hf interstitials.

of the $\mathrm{Ti}^{3+}$ ions with the low Mulliken charges. The $\mathrm{Cu}$ interstitials also reduce the lattice $\mathrm{Ti}^{4+}$ ion but with less extent. By contrast, the $\mathrm{Ti}$ or $\mathrm{Cu}$ interstitials in the $\mathrm{ZrO}_{2}$ do not induce the formation of the lattice $\mathrm{Zr}^{3+}$ ions. Furthermore, the $\mathrm{Cu}$ or $\mathrm{Zr}$ substitutions for the $\mathrm{Ti}$ atoms in the $\mathrm{TiO}_{2}$ also keep the lattice Ti-ions in the +4 valence. As the formation of the $\mathrm{Ti}^{3+}$ trap centers, the $\mathrm{Ti}$ or $\mathrm{Zr}$ interstitials in $\mathrm{TiO}_{2}$ lead to the higher transport coefficients than the $\mathrm{Cu}$ interstitials do. Finally, we propose that the doping of the metal atoms with the valences of +4 or more in their oxides may be beneficial for the formation of the $\mathrm{Ti}^{3+}$ ions in $\mathrm{TiO}_{2}$ and so improves the transport properties. This work may be helpful to guide the doping principle in the metal/ $/ \mathrm{Ti}_{2} /$ metal structure of the resistive random access memory [17].

\section{Conflict of Interests}

The authors declare that there is no conflict of interests regarding the publication of this paper.

\section{Acknowledgments}

The authors acknowledge the support from the National Natural Science Foundation of China under Grants nos. 61076102 and 61272105 and Natural Science Foundation of Jiangsu Province of China under Grants nos. BK2012614 and BK20141196.

\section{References}

[1] D. H. Kwon, K. M. Kim, J. H. Jang et al., "Atomic structure of conducting nanofilaments in $\mathrm{TiO}_{2}$ resistive switching memory," Nature Nanotechnology, vol. 5, no. 2, pp. 148-153, 2010.

[2] R. Waser, R. Dittmann, C. Staikov, and K. Szot, "Redoxbased resistive switching memories nanoionic mechanisms, prospects, and challenges," Advanced Materials, vol. 21, no. 2526, pp. 2632-2663, 2009.
[3] P. A. Mulheran, M. Nolan, C. S. Browne, M. Basham, E. Sanville, and R. A. Bennett, "Surface and interstitial Ti diffusion at the rutile $\mathrm{TiO}_{2}$ (110) surface," Physical Chemistry Chemical Physics, vol. 12, no. 33, pp. 9763-9771, 2010.

[4] A. Stashans, S. Lunell, and R. W. Grimes, "Theoretical study of perfect and defective $\mathrm{TiO}_{2}$ crystals," Journal of Physics and Chemistry of Solids, vol. 57, no. 9, pp. 1293-1301, 1996.

[5] J. He and S. B. Sinnott, "Ab initio calculations of intrinsic defects in rutile $\mathrm{TiO}_{2}$," Journal of the American Ceramic Society, vol. 88, no. 3, pp. 737-741, 2005.

[6] N. Yu and J. W. Halley, "Electronic structure of point defects in rutile $\mathrm{TiO}_{2}$," Physical Review B, vol. 51, no. 8, pp. 4768-4776, 1995.

[7] M. Valden, X. Lai, and D. W. Goodman, "Onset of catalytic activity of gold clusters on titania with the appearance of nonmetallic properties," Science, vol. 281, no. 5383, pp. 16471650, 1998.

[8] R. A. Bennett, P. Stone, N. J. Price, and M. Bowker, "Two $(1 \times 2)$ reconstructions of $\mathrm{TiO}_{2}(110)$ : Surface rearrangement and reactivity studied using elevated temperature scanning tunneling microscopy," Physical Review Letters, vol. 82, no. 19, pp. 3831-3834, 1999.

[9] B. Zeng, D. Xu, M. Tang et al., "Improvement of resistive switching performances via an amorphous $\mathrm{ZrO}_{2}$ layer formation in $\mathrm{TiO}_{2}$-based forming-free resistive random access memory," Journal of Applied Physics, vol. 116, no. 12, Article ID 124514, 2014.

[10] I. Valov and G. Staikov, "Nucleation and growth phenomena in nanosized electrochemical systems for resistive switching memories," Journal of Solid State Electrochemistry, vol. 17, no. 2, pp. 365-371, 2013.

[11] W. Guan, S. Long, Q. Liu, M. Liu, and W. Wang, "Nonpolar nonvolatile resistive switching in $\mathrm{Cu}$ doped $\mathrm{ZrO}_{2}$," IEEE Electron Device Letters, vol. 29, no. 5, pp. 434-437, 2008.

[12] J. P. Perdew, K. Burke, and M. Ernzerhof, "Generalized gradient approximation made simple," Physical Review Letters, vol. 77, no. 18, pp. 3865-3868, 1996.

[13] H. J. Monkhorst and J. D. Pack, "Special points for Brillouinzone integrations," Physical Review B, vol. 13, no. 12, pp. 5188$5192,1976$.

[14] R. S. Mulliken, "Electronic population analysis on LCAO-MO molecular wave functions," The Journal of Chemical Physics, vol. 23, no. 10, pp. 1833-1840, 1955.

[15] J. Yu, M. Jaroniec, H. Yu, and W. Fan, "Synthesis, characterization, properties, and applications of nanosized photocatalytic materials," Journal of Nanomaterials, vol. 2012, Article ID 783686, 3 pages, 2012.

[16] D. M. Ramo, J. L. Gavartin, A. L. Shluger, and G. Bersuker, "Spectroscopic properties of oxygen vacancies in monoclinic $\mathrm{HfO}_{2}$ calculated with periodic and embedded cluster density functional theory," Physical Review B, vol. 75, no. 20, Article ID 205336, 2007.

[17] C. Y. Liu, Y. Y. Tsai, W. T. Fang, and H. Y. Wang, "Resistive switching characteristics of a $\mathrm{SiO}_{x}$ Layer with $\mathrm{CF}_{4}$ plasma treatment," Journal of Nanomaterials, vol. 2014, Article ID 703463, 5 pages, 2014. 

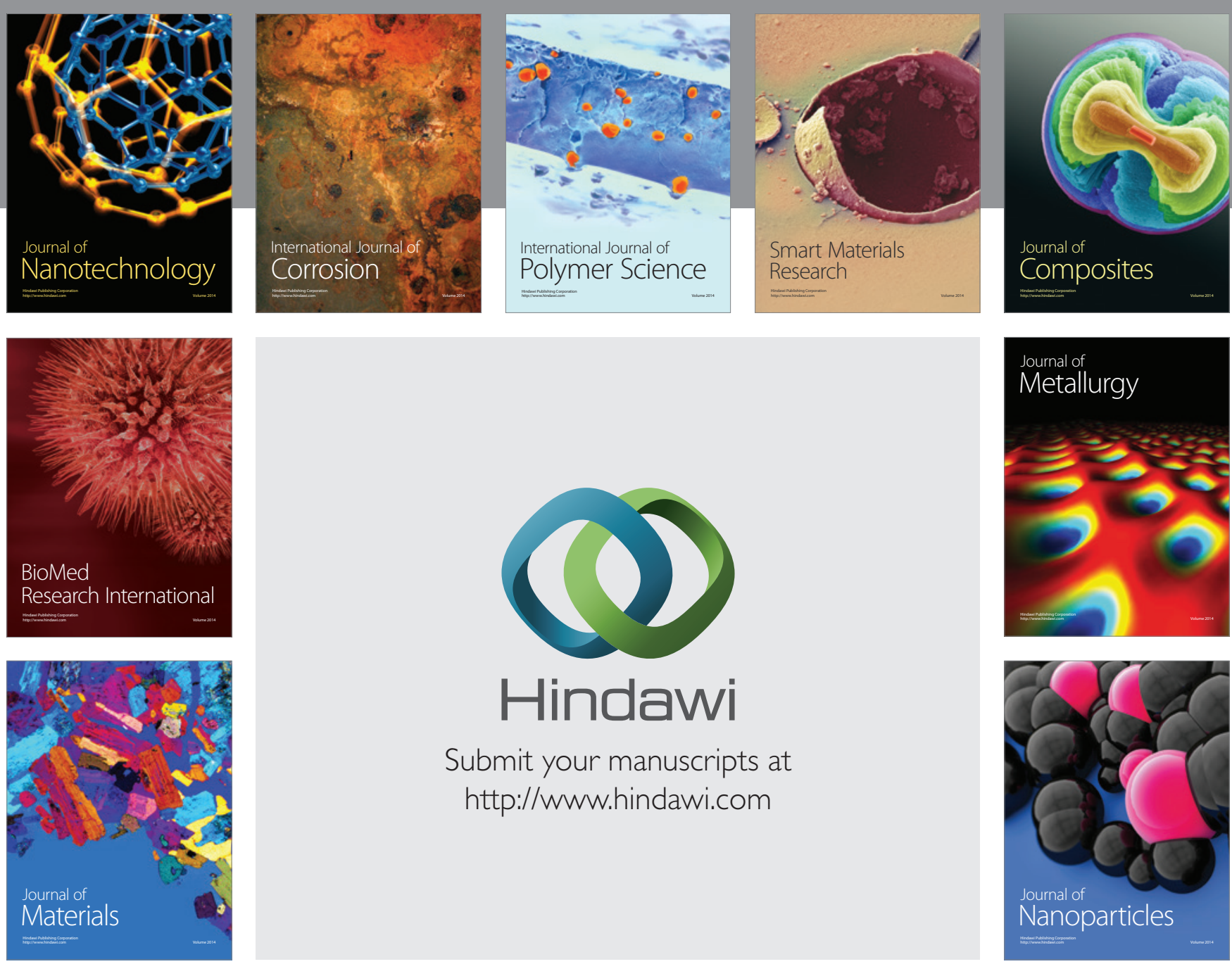

Submit your manuscripts at http://www.hindawi.com
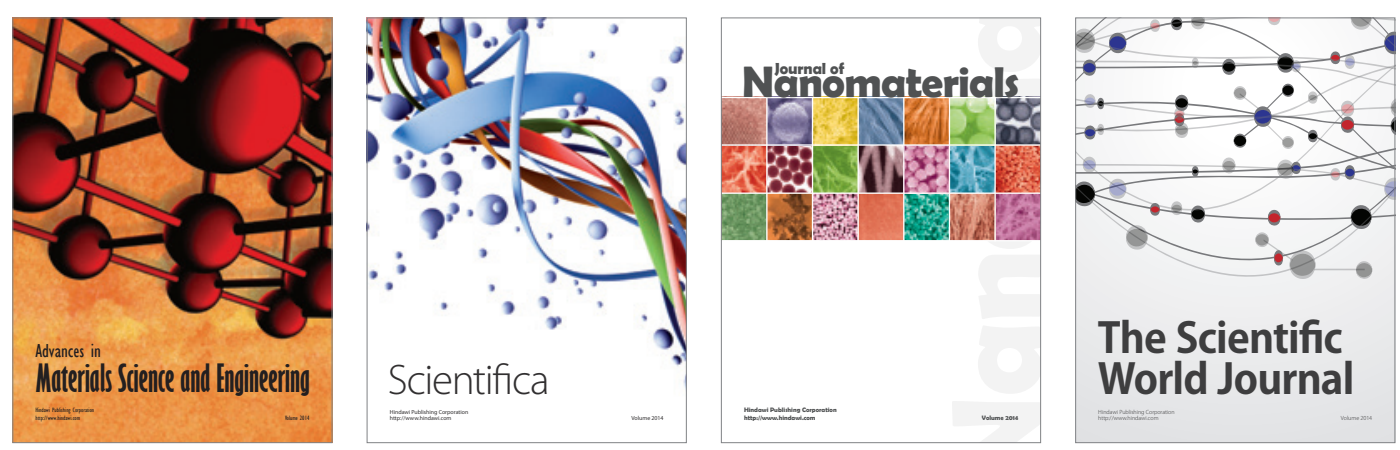

\section{The Scientific World Journal}
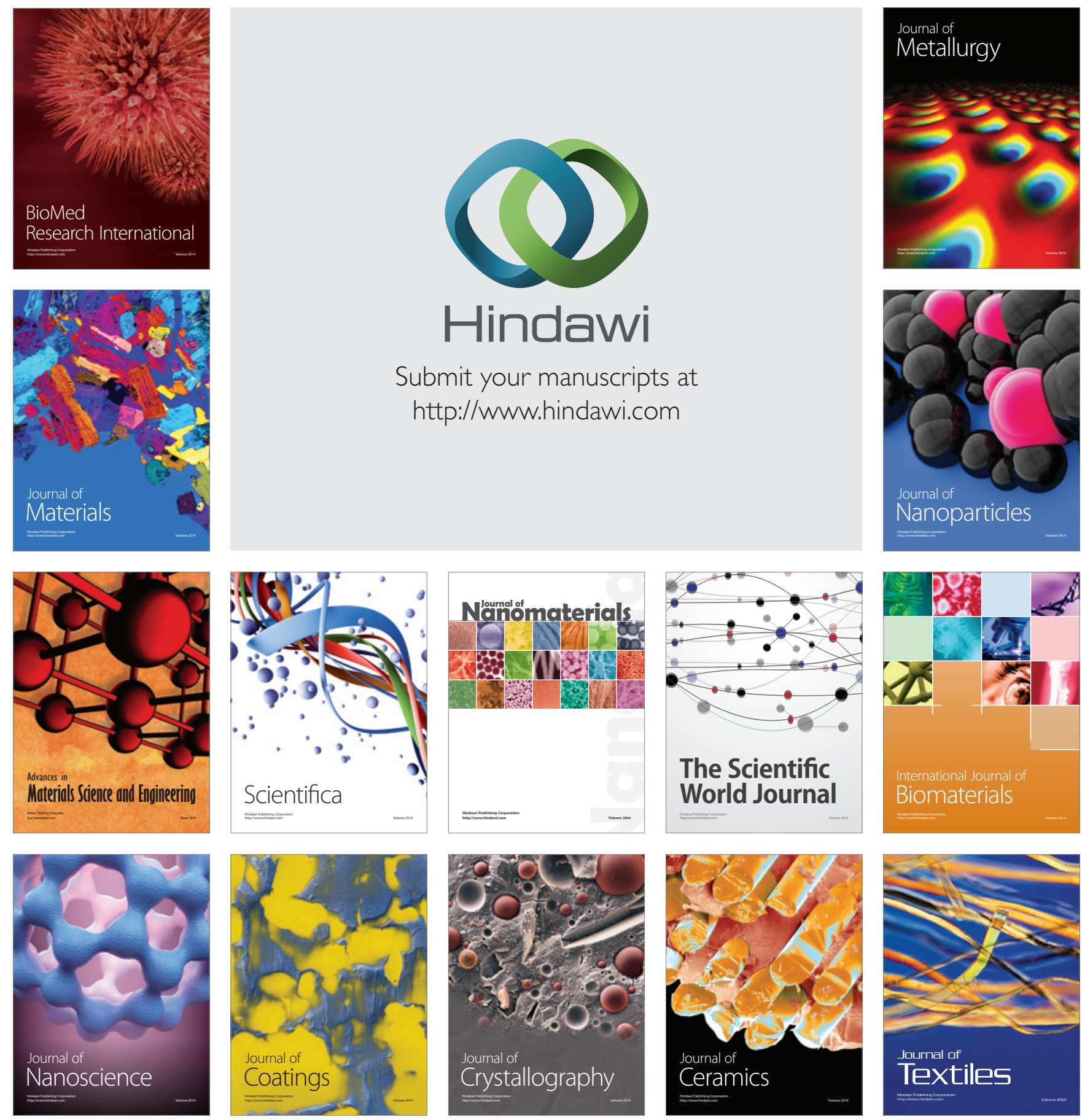